\title{
El Movimiento Izquierda Revolucionaria (Praxis) y la construcción del Partido Obrero (1955-1960)
}

\author{
The Movimiento Izquierda Revolucionaria (Praxis) and the construction of the \\ Partido Obrero (1955-1960)
}

Javier Díaz*

\begin{abstract}
Resumen: En este trabajo analizamos el desenvolvimiento histórico de la línea política del Movimiento Izquierda Revolucionaria (Praxis), enfocándonos en su posicionamiento respecto de la necesidad de la construcción de un partido obrero como medio para consumar la revolución socialista en Argentina.
\end{abstract}

Palabras Clave: Izquierda, Revolución, Partido Praxis, Socialismo, MIR

\begin{abstract}
This paper analyzes the historical development of the political line of the Movimiento Izquierda Revolucionaria (Praxis), focusing on its stance regarding the need of a worker's party in order to accomplish the socialist revolution in Argentina.
\end{abstract}

Key Words: Left, Revolution, Party Praxis, Socialism, MIR

Recibido: $28 / 02 / 2017$

Aceptado: 11/06/2017

\section{Introducción}

El presente artículo constituye la exposición de los primeros resultados de nuestra investigación de tesis de licenciatura en Historia, cuyo objeto es la reconstrucción de la trayectoria del Movimiento Izquierda Revolucionaria (Praxis) desde una perspectiva de historia social. En este trabajo analizamos el desenvolvimiento histórico de la línea política del Movimiento Izquierda Revolucionaria (Praxis) enfocándonos en un aspecto particular: su posicionamiento respecto de la necesidad de la construcción de un partido obrero como medio para consumar la revolución socialista en Argentina. Nos limitaremos aquí a la

\footnotetext{
*Argentino, Universidad de Buenos Aires, javierdiazbuenosaires@hotmail.com
} 
segunda mitad de la década del 50, etapa que coincide con la publicación de Revolución, primer periódico de la organización.

La trayectoria de Praxis está unida a la de su fundador y principal dirigente. Abogado y profesor de historia formado en el pensamiento liberal democrático, Silvio Frondizi (1907-1974) adoptó desde 1946 el materialismo histórico como método de análisis. Entre 1944 y 1949 reunió a sus primeros colaboradores como Marcos Kaplan, Eugenio Werden y Ricardo Napurí. Frondizi pensaba que la primera tarea de un revolucionario, premisa para el ulterior desarrollo de una organización, era la elaboración de un programa marxista, del cual carecían -a su juicio- los diversos partidos y grupos políticos existentes. Por ello se dedicó a redactar ese programa, que finalmente publicó con el nombre de La Realidad Argentina. Allí desarrolló su teoría de la integración mundial capitalista y su análisis de la formación social nacional.

Hasta 1955 el grupo Praxis funcionó como un centro de estudio, formación teórica y difusión de ideas a través de folletos y libros. Según las memorias de Napurí,

(...) la primera etapa del proyecto Praxis consistiría en una escuela de formación política de la que saldrían cuadros-militantes, capaces de impulsar un proyecto estratégico. Pero en este camino, y en la medida de las exigencias sociales y políticas, la forma de salir hacia afuera descansaría en hacer conocer polémicamente su pensamiento global. $\mathrm{O}$ sea, una batalla por las ideas socialistas. Algo así como un "centro político", que tendría a Silvio como su mentor principal. Cumplida esta fase, se evaluaría si todo lo acumulado podía desembocar en la construcción de una organización (...). ${ }^{1}$

Silvio Frondizi fundamentó esta concepción "etapista" de la formación de una organización con estas palabras que escribió a mediados de la década del 50:

hemos enfrentado y buscado solucionar estos problemas, más que en la agitación incontrolada de masas, de corta duración y poco efecto, dedicando atención a la formación de cuadros medios obreros, manuales e intelectuales, que pueden llegar a ser los grandes conductores sociales de mañana. ${ }^{2}$

En noviembre de 1955 vio la luz el periódico de la organización: Revolución. Órgano argentino de esclarecimiento político, bajo la dirección de Marcos Kaplan (sólo el primer número se tituló Liberación). La perentoria situación política (golpe de Estado), con sus consecuencias en términos de deliberación popular, probablemente haya representado una exigencia de acción. En este contexto la iniciativa parece haber correspondido al grupo

\footnotetext{
${ }^{1}$ Napurí, Ricardo, Pensar América Latina. Crónicas autobiográficas de un militante revolucionario, Buenos Aires, Herramienta, 2009, p. 133.

${ }^{2}$ Frondizi, Silvio, La Realidad Argentina. Ensayo de interpretación sociológica. Tomo II: La revolución socialista, Buenos Aires, Praxis, 1960 (2 ed.; $1^{\text {a }}$ ed.: 1956), pp. 226-227.
} 
de jóvenes que se había acercado a Praxis a lo largo de los últimos años del gobierno de Perón y "hacia 1955 pugnaba por romper el círculo de hierro de la actividad intelectual y propagandística y lanzarse a la práctica política"3. "Serán los jóvenes convocados por los cursos de Silvio Frondizi e interpelados por su obra los que empujarán al profesor de teoría política (...) a la práctica política activa" 4 .

Esta novedad coincidió con la publicación en dos tomos (en 1955 y 1956 respectivamente) de La Realidad Argentina. Ensayo de interpretación sociológica. Con una prensa y un programa Praxis comenzó a crecer y a intentar acercarse a la clase obrera.

Hacia afuera Praxis divulgaba su pensamiento político, además de las universidades, en centros culturales y en uno u otro sindicato. Y ya no sólo a través de Silvio Frondizi, Marcos Kaplan, Eugenio Werden y Ricardo Napurí, sino asimismo por los cordones del creciente número de jóvenes propagandistas que iban más lejos del medio estudiantil y universitario para ir acercándose, con indudables dudas de aprendices a otros medios sociales, incluso obreros. ${ }^{5}$

Un punto de inflexión se produjo en las elecciones de febrero de 1958. Mientras que la mayoría de la izquierda llamó a votar por Arturo Frondizi, acompañando la orden de Perón, el MIR-P lanzó una campaña por el voto en blanco. El giro derechista conocido como "traición Frondizi" (mantenimiento de la proscripción al peronismo, Plan Conintes, aprobación de la educación religiosa, privatizaciones) y luego la Revolución Cubana provocaron la radicalización política de amplios sectores de la pequeña burguesía, que buscaron empalmar con la alta combatividad obrera ${ }^{6}$. Esta situación colocó al MIR-P en un lugar políticamente privilegiado que le permitió captar a un número considerable de jóvenes. Así fue cómo se desarrolló durante 1958 y 1959. A fines de los 50 el MIR-Praxis "contaba con un centenar de miembros encuadrados en una organización celular"7, alcanzando entonces su máximo crecimiento.

A partir de 1959 Silvio realizó un viraje teórico y político cuyo tenor "populista" fue señalado por Tarcus y que desembocó en la salida del folleto "Bases y punto de partida para una solución popular" (1960). El nuevo periódico, Movimiento, que vio la luz en 1961, expresó este giro. La consecuencia fue la primera gran crisis del MIR-P y la escisión de diversos grupos de militantes. Finalmente, Praxis terminó de disolverse en 1964. Silvio continuó su actividad defendiendo presos políticos y en los años 70 integró, junto a figuras como Agustín Tosco y Rodolfo Ortega Peña, el Frente Antiimperialista por el Socialismo (FAS), organización impulsada por el Partido Revolucionario de los Trabajadores (PRTERP). Fue asesinado por la triple A en 1974.

En cuanto a los trabajos publicados hasta la fecha en torno a nuestra temática, no

${ }^{3}$ Tarcus, Horacio, El marxismo olvidado en la Argentina: Silvio Frondizi y Milcíades Peña, Buenos Aires, El cielo por asalto, 1996, p. 143.

${ }^{4}$ Ibid, p. 141.

${ }^{5}$ Napurí, op. cit., pp. 152-153.

${ }^{6}$ Altamirano, Carlos, Bajo el signo de las masas (1943-1973), Buenos Aires, Emecé, 2007, pp. 100-101.

${ }^{7}$ Tarcus, op. cit., p. 144. 
existe bibliografía específica, ya que no hay materiales que tengan como objeto central de estudio al MIR-P (1955-1964) o a su antecedente, el Grupo Praxis (1949-1955). La mayor parte de las fuentes secundarias refiere al pensamiento de Silvio Frondizi.

Con relación a Praxis Horacio Tarcus fue pionero en la reconstrucción de su historia y hasta el día de hoy el único historiador que se ha ocupado de ella. Cuatro acápites, distribuidos en dos capítulos del libro, están dedicados a describir respectivamente la formación, los rasgos distintivos, la política y la crisis del MIR-P. Para definir el tipo de organización que buscaban construir los praxistas el autor basó su análisis en dos fuentes. Por un lado en un pasaje del prólogo, fechado en agosto de 1956, a un libro de Kaplan, en el cual Silvio Frondizi realizó la siguiente observación:

(...) la solución de la crisis contemporánea no será alcanzada en un aspecto parcial, sino en la totalidad de la vida humana, tanto en el plano económico como en el político, social, espiritual, de la actividad creadora, sexual, familiar, de la vivienda, etc. Por ende, un grupo revolucionario actual debe tender a planear y desarrollar en su seno, con un sentido liberador, todas las actividades del hombre, es decir a preformar en pequeño la sociedad socialista por cuyo alumbramiento milita. ${ }^{8}$

El concepto expresado por primera vez en esta frase fue retomado, siguiendo a Tarcus, por el folleto de Marcos Kaplan de 1960, Política y vida cotidiana, al cual el historiador calificó como "un verdadero manifiesto de la nueva izquierda" .

El texto es, al mismo tiempo que una crítica aguda y descarnada, un llamamiento por una izquierda y una militancia de nuevo tipo. Su agenda será: el partido como "anticipación" de la sociedad futura, la búsqueda del "militante integral", la crítica de la vida cotidiana, el abandono del sustituismo o del paternalismo sobre las masas, la promoción de las prácticas colectivas y autogestivas en la sociedad y en el partido... ${ }^{10}$

En un artículo redactado algunos años después, Samuel Amaral ${ }^{11}$ se limitó a deducir, a partir del examen de los dos tomos de La Realidad Argentina, la idea que su autor tenía acerca de la forma de hacer la revolución en este país. "Frondizi creía que las masas solas, sin dirección, no producirían la revolución. Su tarea política y la que proponía a sus seguidores era construir esa dirección" 12 . Luego de citar una frase en la que el abogado defendía el papel del partido en la lucha contra el imperialismo, Amaral infiere que el "partido de clase, entonces, surgiría en medio de la lucha revolucionaria. Antes

\footnotetext{
${ }^{8}$ Silvio Frondizi, "Prólogo", en Kaplan, Marcos, Economía y política del petróleo argentino (1939-1956), Buenos Aires, Praxis, 15 de enero de 1957, p. 9.

${ }^{9}$ Tarcus, op. cit., p. 145.

${ }^{10}$ Ibid., p. 147.

11 Amaral, Samuel, "Silvio Frondizi y el surgimiento de la nueva izquierda", Universidad del CEMA, documento de trabajo $n^{\circ} 313,2006$, pp. 30-42.

${ }^{12}$ Ibid., p. 35.
} 
estaba la acción de las masas y la conformación de una dirección: ambas, se supone, se encontrarían en el momento del 'ascenso revolucionario' y de ese encuentro nacería el partido de clase" $" 13$. El mérito de este análisis es que comprendió que para Frondizi se debía formar una dirección como paso previo a la creación del partido. La conclusión del artículo es acertada en lo que refiere a la primera mitad de la década del 50: "La peor de las imprecisiones de Frondizi” residía "en su visión de la actividad política como una tarea de formación de cuadros a la espera de que el ascenso revolucionario de las masas los convocara, en un momento impreciso, a la acción"14. Pero no da cuenta del período posterior a 1955.

En este trabajo profundizamos el análisis ampliando las fuentes y utilizando el conjunto de las publicaciones de la organización. Recurriendo principalmente a Revolución, periódico del MIR-P entre 1955 y 1960, analizaremos cómo se formó a lo largo del tiempo y qué alteraciones sufrió el concepto que los praxistas tuvieron acerca de la organización que debían crear para poder llevar a cabo la revolución socialista en la Argentina.

Nuestra hipótesis es que este aspecto de la concepción praxista es fundamental para comprender el desenvolvimiento posterior de la organización. En efecto, a partir de 1960 el MIR-P atravesará una crisis que tendrá como consecuencia la formación, por parte de antiguos miembros, de nuevas organizaciones tales como el Movimiento Izquierda Revolucionaria Argentino (MIRA) o Política Obrera (PO). En futuras investigaciones intentaremos poner de relieve en qué medida los desarrollos teóricos de los años 50 determinaron los debates de los praxistas posteriores a la Revolución Cubana.

\section{El MIR-Praxis y la necesidad del partido obrero revolucionario}

El primero en plantear la necesidad de formar un partido obrero fue Silvio Frondizi. En el segundo tomo de La Realidad Argentina, escrito en 1954, consideró que entre las tareas inmediatas de la nueva sociedad se encontraba la lucha contra el imperialismo, la cual "podrá ser realizada solamente por un partido que se fundamente en clases, como el proletariado y la pequeña burguesía pauperizada" "15, oración que reutilizó al año siguiente en su artículo del primer número del periódico de la organización ${ }^{16}$. En diciembre de 1955 publicó un escrito en El Líder en el cual aseguraba que "el movimiento sindical debe tender hacia una acción política, es decir, a la formación de un partido obrero" "17. Ambos textos de fines del 55 fueron reeditados por el MIR-P en Doce años de política argentina, compilación publicada en 1958. En el libro Las izquierdas en el proceso político argentino, que vio la luz en 1959, Carlos Strasser reprodujo entrevistas a dirigentes de distintas corrientes políticas, incluyendo en primer lugar a Silvio Frondizi. Éste repitió en el

\footnotetext{
${ }^{13}$ Ibid., p. 37.

${ }^{14}$ Ibid., p. 41.

${ }^{15}$ Frondizi, Silvio, La Realidad Argentina ..., op. cit., pp. 237-238.

${ }^{16}$ Silvio Frondizi, "La encrucijada argentina", en Liberación nro. 1 (octubre de 1955), reproducido en Frondizi, Silvio, Doce años de política argentina, Buenos Aires, Praxis, 1958 [1945-1957], p. 66.

${ }^{17}$ Silvio Frondizi, "El dilema económico-social del país", en El Líder (18 de diciembre de 1955), reproducido en Frondizi, Silvio, Doce años..., op. cit., p. 73.
} 
reportaje muchas de las expresiones utilizadas en sus trabajos anteriores, pero introdujo también modificaciones. Hizo referencia, por ejemplo, al "grave problema -tal vez el más grave que enfrenta la revolución socialista en el mundo- sobre las relaciones entre masa, partido y dirección"18. Más importante para nuestro tema fue que, luego de afirmar que ya no debía pensarse en una "revolución democrático-burguesa" sino que se trataba de realizar tareas democrático-burguesas en la marcha de la revolución socialista, transcribió casi literalmente el pasaje citado de La Realidad Argentina pero modificó sustancialmente la fórmula empleada: "Entre estas tareas inmediatas figura: la lucha contra el imperialismo, que sólo puede ser realizada por un partido marxista revolucionario que se fundamente en las masas"19. Aunque el libro fue publicado en octubre, su prólogo está fechado en junio y, como observó Rath, probablemente el reportaje haya sido realizado en 1958, es decir antes del triunfo de la Revolución Cubana, porque ésta no es mencionada ni una sola vez ${ }^{20}$. Podemos afirmar, en resumen, que al menos hasta 1958 Silvio Frondizi defendió la necesidad de formar un partido obrero revolucionario.

\section{El partido obrero como tarea inmediata}

Revolución vio la luz entre noviembre de 1955 y mayo de 1960, alcanzando en total 35 números. La interpelación a los trabajadores fue un componente central de su discurso: en todos y cada uno de los periódicos hubo artículos acerca del movimiento obrero.

Desde 1955 hasta 1960, desde el primer hasta el último número de Revolución, se sostuvo de parte del conjunto del MIR-P la necesidad de construir el partido obrero revolucionario. Por lo tanto, la organización no se consideraba a sí misma como idéntica a ese partido que debía hacer la revolución sino como su base, su núcleo o germen. La necesidad de un partido obrero era explicada, según veremos, como producto de la necesidad de que la clase obrera contara con un instrumento de combate capaz de tomar el poder. Una declaración en el primer número expresaba los siguientes conceptos:

En base a sus organizaciones, los trabajadores podrán resistir eficazmente la ofensiva reaccionaria de la burguesía, mantener y profundizar las conquistas, intervenir cada vez más en la política argentina. Esta intervención política del sindicalismo obrero deberá ser independiente de los partidos políticos existentes, que han usado y usan al movimiento obrero no para hacer progresar a los trabajadores, sino para servir intereses ajenos a la masa proletaria y a las necesidades nacionales. Los obreros deben tratar de crear a la mayor brevedad posible su propio partido político, apoyado y dirigido directamente por las clases trabajadoras, y destinado exclusivamente a servir sus intereses. ${ }^{21}$

\footnotetext{
${ }^{18}$ Strasser, Carlos (coord.), Las izquierdas en el proceso político argentino, Buenos Aires, Palestra, 1959, p. 42.

${ }^{19}$ Ibid., p. 43.

${ }^{20}$ Rath, Christian, "El MIR (Praxis) en la historia del movimiento obrero argentino", en En defensa del marxismo nro. 45, Buenos Aires, Rumbos, octubre de 2015, p. 68.

${ }^{21}$ Centro de Renovación Sindical, “A los trabajadores”, en Liberación nro. 1 (nov. 1955), p. 3, subrayado nuestro.
} 
En un artículo de tapa del segundo número se desarrollaron estos conceptos:

Los obreros deben trabajar desde ya por la creación a corto plazo de su propio partido político (...) El surgimiento de un auténtico partido obrero servirá, no sólo para defender y profundizar las conquistas y el progreso de los trabajadores, sino también como ejemplo, caudillo y motor para las luchas de otras capas oprimidas de la sociedad argentina. ${ }^{22}$

Las frases subrayadas evidencian que Praxis postulaba la creación del partido obrero como una tarea inmediata, no como un objetivo a alcanzar en el futuro. El tercer número del periódico prueba con mayor contundencia la centralidad que la organización le daba a esta idea. En efecto, el artículo publicado en primera plana se titula "Los trabajadores deben construir su propio partido político" y tenía la siguiente conclusión:

Los más conscientes y avanzados de los trabajadores manuales e intelectuales, de los activistas sindicales y políticos, del estudiantado, etc., independientes o afiliados a organizaciones ya existentes, deben trabajar desde ahora mismo con todas sus fuerzas por la constitución de un grande y auténtico partido de las clases trabajadoras.

El primer paso para ello es el cambio de ideas y la discusión sobre los problemas sociales y políticos del país, y sobre el posible programa para el nuevo partido. (...) En fábricas y talleres, oficinas y sindicatos, barrios y sociedades culturales, deben formarse grupos de adherentes a la idea de formar un nuevo y verdadero partido de los trabajadores. (...)

La necesidad de construir el gran partido del pueblo trabajador es sentida hoy por capas cada vez más amplias de la población, y se manifiesta ya en la multiplicación a través del país de grupos y tendencias que aspiran a ello. De la realización efectiva y rápida de esta finalidad dependerá el resultado de las grandes batallas sociales y políticas que se preparan desde ahora y para el futuro inmediato en el seno de la sociedad argentina. ${ }^{23}$

En el número siguiente el director del periódico, Marcos Kaplan, repetía lo que podemos considerar una muletilla de la organización: "Los trabajadores pueden y deben intervenir cada vez más en la política argentina, creando a corto plazo su propio partido, apoyado y dirigido por ellos, y destinado a servir sus intereses" ${ }^{24}$. Ángel Marini afirmaba en otra nota que "los telefónicos deben unirse a todos los trabajadores del país para construir su propio partido político" $" 25$. Un año después Marini concluía su texto con esta afirmación:

${ }^{22}$ Revolución nro. 2 (dic. 1955), pp. 1-2, subrayado nuestro.

${ }^{23}$ Revolución nro. 3 (feb. 1956), p. 6, subrayado nuestro.

${ }^{24}$ Marcos Kaplan, "La clase trabajadora no necesita tutores", en Revolución nro. 4 (mayo 1956), p. 5.

25 Ángel Marini, "Carta de un telefónico”, en Revolución nro. 4 (mayo 1956), p. 7, subrayado en el original. 
La construcción de un partido obrero revolucionario como vanguardia de los intereses del proletariado de la ciudad y el campo (...) será la condición necesaria para superar esta encrucijada histórica en que nos encontramos ${ }^{26}$.

Queda claro que el MIR-Praxis no sólo defendía la idea de construir un partido obrero, sino que la consideraba como una tarea necesaria e ineludible. No se trataba de la única coincidencia con la práctica leninista. También se sostenía la táctica de frente único obrero, adoptada por los primeros congresos de la III Internacional y, desde 1935, abandonada por el stalinismo y reivindicada solamente por el trotskismo. "Al frente único de la burguesía, los trabajadores deben oponer su frente único proletario" 27 , se afirmaba en Revolución ya en 1955. El número de agosto de 1957 llevaba como título en primera plana: "Frente Único de los Trabajadores. Para resistir la ofensiva del gran capital y crear la dirección de la revolución argentina".

Es interesante especificar que la creación de una organización revolucionaria era planteada como una necesidad para tomar el poder del Estado. Por ejemplo, Marcos Kaplan, en su folleto dedicado a analizar al radicalismo, dedicaba las últimas páginas a plantear su propia perspectiva política en términos distantes a los que caracterizarán su obra de 1960:

La defensa y profundización de sus intereses y conquistas lleva al proletariado a enfrentarse cada vez más con las estructuras y órganos de poder del gran capital, y a presionar y afectar con audacia y profundidad crecientes las bases mismas del sistema social vigente, hasta llegar a plantearse, tarde o temprano, la necesidad de tomar el estado en sus manos. Claro está que se ha tratado y se tratará necesariamente de un proceso complejo, contradictorio, de duración y alternativas imprevisibles, en cuya trayectoria influirán primordialmente el ritmo objetivo del proceso crítico mundial y nacional, la rapidez con que surja una vanguardia obrera organizada y combativa, y la medida en que esa vanguardia y el proletariado todo sean capaces de combinar la lucha por sus intereses propios con la defensa y satisfacción de los intereses de otras capas oprimidas del país (pequeña burguesía urbana y rural, intelectuales esclarecidos, etc.). ${ }^{28}$

\section{Tensiones}

La línea de Praxis adquiere una formulación diferente en el artículo de Aldo Comotto titulado "La Vanguardia Estudiantil y la Construcción del Partido Obrero".

\footnotetext{
${ }^{26}$ Ángel Marini, "El movimiento obrero debe combinar la acción gremial con la lucha política", en Revolución nro. 7 (mayo 1957), p. 6.

${ }^{27}$ Revolución nro. 2 (dic. 1955), pp. 1-2.

${ }^{28}$ Kaplan, Marcos, La crisis del radicalismo, Buenos Aires, Praxis, 31 de enero de 1958, p. 43, subrayado en el original.
} 
Para que el surgimiento de un partido obrero se produzca y sea aceptado por la clase trabajadora, necesita sufrir un proceso de etapas preliminares, dadas las circunstancias especiales por las que ha pasado la clase obrera argentina en su vida política. En nuestro país, no ha existido como por ejemplo en Rusia, un partido obrero de clase que canalizara el ascenso político de un naciente proletariado. El partido comunista y el partido socialista, limitándose a planteos reformistas, no supieron captar el sentido revolucionario de las movilizaciones obreras del año 45. Esto, permitió que la burguesía controlara ese ascenso mediante un experimento bonapartista. Ahora la clase obrera se halla ante la tarea de crear su propio partido estructurado en base a un equipo de vigorosa concepción revolucionaria. Pero los mitos e ídolos propios de una primera experiencia no concluida todavía están enraizados en el seno de la clase trabajadora. Por eso es tarea de los elementos más esclarecidos del proletariado y la pequeña burguesía, especialmente la culta, trazarse una estrategia preliminar para que el futuro partido obrero irrumpa con éxito y marche hacia la victoria. Es así, como un partido revolucionario de masas, necesita para levantarse una proyección en tres etapas, que aunque no con un orden de prelación matemático, es conveniente cumplir dadas nuestras circunstancias:

$\left.1^{\circ}\right)$ Desarrollar la teoría revolucionaria (...). La relación de clase que existe en la actualidad nos permite inducir que es la pequeña burguesía especialmente la culta y las masas estudiantiles las que pueden tener un papel importante en esta etapa.

$2^{\circ}$ ) Crear un equipo de cuadros medios o vanguardia revolucionaria (...). Es por lo tanto tarea ineludible seleccionar del proletariado y de la pequeña burguesía los elementos más esclarecidos que equipados con una teoría revolucionaria y fogueados por una militancia política y sindical activa, llevarán por buen recaudo a las masas trabajadoras hacia su liberación definitiva. (...)

$\left.3^{\circ}\right)$ Crear un partido de masas cerebro de la revolución: Teniendo esas premisas ya plasmadas; habiendo un cierto ascendiente por parte de los cuadros en el grueso de la masa, la creación de un partido surge de las necesidades ante la acción de los cuadros. Las vanguardias habrán esclarecido ideológicamente, denunciando permanentemente los anzuelos y trampas políticas que la burguesía les tiende a sus enemigos; habrán hablado de las necesidades de un partido, etc. En fin, el partido surge y encuentra respuesta inmediata, en esa masa ya esclarecida, movilizada y politizada por los cuadros y las vanguardias. En resumen, el rol de la pequeña burguesía en la faz creativa de un partido obrero radica en contribución a la elaboración de una teoría revolucionaria; en la intervención en la organización de cuadros medios que inyectarán la teoría revolucionaria en la masa trabajadora y levantarán los cimientos de 
un partido de clase. ${ }^{29}$

Ubicamos aquí una inflexión en el discurso praxista, la cual buscaba superar una contradicción interna que está expresada en la nota. En efecto, primero se sostiene que "ahora la clase obrera se halla ante la tarea de crear su propio partido" para pocas líneas después buscar "que el futuro partido obrero irrumpa con éxito". ¿Qué hacía que el "ahora" se desdoble en un "ahora" y un "futuro"? ¿Qué había en el medio, literalmente, de estas dos afirmaciones? La constatación de que "los mitos e ídolos propios de una primera experiencia no concluida todavía están enraizados en el seno de la clase trabajadora", es decir de la persistencia del peronismo en el movimiento obrero. Comotto estaba expresando la voluntad de sortear un obstáculo del cual Silvio Frondizi no había dado cuenta en La Realidad Argentina, escrito antes de la caída de Perón. En efecto, como ha sido puesto de relieve por $\mathrm{Coggiola}^{30}$, $\mathrm{Amaral}^{31}$ y $\mathrm{Rath}^{32}$, Frondizi había concebido al peronismo únicamente en cuanto régimen político bonapartista pero no en cuanto movimiento político e ideológico. En 1957 había no un régimen, pero sí un movimiento y una ideología peronistas hegemónicos en la clase obrera.

La inflexión tiene un segundo aspecto. La "construcción de un partido obrero revolucionario como vanguardia de los intereses del proletariado" (subrayado nuestro), que había defendido Ángel Marini pocos meses antes, se había desdoblado ahora en una vanguardia, identificada con un equipo de cuadros medios, por un lado, y un partido de masas, creado sobre la base de la acción previa de la vanguardia, por el otro.

El texto no aclara en qué etapa se hallaba en ese momento el MIR-Praxis. Nos inclinamos por la idea de que en la visión praxista la primera etapa estaba ya cumplida y se estaba atravesando la segunda. Aun así, la novedad consiste en que la creación del partido obrero había dejado de ser una tarea a realizarse en el corto plazo, "a la mayor brevedad posible", para pasar a ser la fase siguiente dentro de una estrategia que requería cumplir con una tarea previa. El partido se había desplazado hacia el mediano plazo.

Un nuevo desarrollo de la idea de construir el partido revolucionario aparece en un “editorial sindical" de Claudio Perinetti, en el cual afirmaba:

El paso a la lucha política revolucionaria será la única garantía válida para el progreso económico del pueblo trabajador. (...) Máxime cuando esta lucha, para ser efectiva, necesita (...) encauzarse en el único instrumento adecuado para quebrar la represión y pasar a la ofensiva: el partido obrero. (...)

En [sic] estas condiciones negativas pueden derivar, en la medida en que no se les salga al paso una vanguardia política revolucionaria en camino hacia la formación urgente del partido obrero, en un

\footnotetext{
${ }^{29}$ Aldo A. C[o]motto, "La Vanguardia Estudiant[i]1 y la Con[s]trucción del Partido Obrero", en Revolución nro. 10 (dic. 1957), pp. 3-4, subrayado en el original.

${ }^{30}$ Coggiola, Osvaldo, Historia del trotskismo en Argentina y América Latina [1985-1986], Buenos Aires, ryr, 2006, pp. 186-187.

${ }^{31}$ Amaral, Samuel, op. cit., pp. 34 y 40.

${ }^{32}$ Rath, Christian, op. cit., pp. 70-71.
} 
fortalecimiento de la reacción, al agudizarse las tendencias fascistas de amplias capas de la pequeña burguesía por obra de la crisis económicapolítica, y gracias a un estado de desaliento y cansancio de la clase trabajadora ante la falta de perspectivas superadoras visibles. (...) 1959 deberá contener los cimientos de un partido revolucionario de la clase obrera. Quienes se digan a su servicio, y rehúsen su esfuerzo a esta tarea, serán arrojados al rincón de las cosas inservibles en el curso del futuro ascenso obrero y popular. ${ }^{33}$

Nuevamente el mediano plazo. Es evidente la tensión entre la necesidad inmediata de un partido revolucionario y la distancia que separaba a Praxis de éste. El partido obrero, por otro lado, era concebido fundamentalmente como instrumento de combate.

En el mismo periódico fue publicado un artículo de Marcos Kaplan, según el cual

es imprescindible la construcción de un partido obrero de tipo revolucionario, que se enraíce verdaderamente en las masas proletarias y populares, conquiste su dirección y la de sus sindicatos, y dirija la lucha por la revolución anticapitalista y antiimperialista y por la construcción de la sociedad socialista. Sin partido obrero revolucionario no es ya posible una acción sindical eficaz y progresista. ${ }^{34}$

El partido aparece como condición previa para alcanzar la dirección de los sindicatos. Era, por lo tanto, necesario para poder conquistar la conciencia de la mayoría de los trabajadores. Debía ser además un partido de combate, que dirigiera la lucha por la revolución. En la continuación de este trabajo encontramos un desarrollo mayor.

(...) el Movimiento Izquierda Revolucionaria (Praxis) retoma la concepción marxista - leninista del partido, como organización centralizada, rigurosamente delimitada, predominantemente clandestina, y compuesta por militantes. Pero afirmamos asimismo la necesidad de replantear y desarrollar dicho esquema básico a la luz de las experiencias nacionales e internacionales de este siglo y en función de la realidad argentina y latinoamericana. Hoy nos ocupamos concretamente de la experiencia del M.I.R. (Praxis) en la construcción del partido revolucionario. (...) Al retomar el esquema marxista básico de partido revolucionario, el M.I.R. (Praxis) [ha] concedido una importancia primordial a la formación de los cuadros. (...)

Los beneficios del método praxista.

La preocupación activa y sistemática por la formación integral de sus cuadros ha ido permitiendo al M.I.R. (Praxis), cada vez más, el logro [de] varias finalidades importantes, tales como las siguientes:

\footnotetext{
${ }^{33}$ Claudio Perinetti, “1958. Seguidismo político y espontaneidad en el movimiento obrero”, en Revolución nro. 21 (enero de 1959), p. 4, subrayado nuestro.

${ }_{34}$ Marcos Kaplan, "Seguidismo oportunista o realismo revolucionario", en Revolución nro. 21 (enero de 1959), p. 3, subrayado en el original.
} 
Ha favorecido el surgimiento de un tipo medio de militante, a la vez homogéneo y humanamente rico, que tiende a superar los perjuicios de la especialización, del diletantismo y del origen clasista, que [e]lude a la vez las limitaciones del intelectualismo abstracto y del practicismo mezquino, del aburguesamiento alienante y del obrerismo primitivo.

Ha facilitado la promoción de un creciente predominio proletario en la composición del Movimiento, y la liquidación o control estricto de los hábitos pequeñoburgueses de pensamiento y acción que amenazan permanentemente a los movimientos de izquierda. ${ }^{35}$

Se trata quizá de la primera vez en que la organización asume explícitamente la concepción leninista de partido político. Kaplan no especificó en qué aspectos concretos la doctrina de Lenin debía ser actualizada o adaptada a la Argentina. La importancia dada a la formación de cuadros era presentada como consecuencia de retomar aquel esquema básico, pero la veta novedosa consistía en el énfasis dado a la formación "integral”. Sin embargo, ésta era definida a partir de sus resultados. No se explicaba el método, sino sus beneficios. Kaplan desarrolló esta línea al año siguiente en su folleto Política y vida cotidiana.

La necesidad del partido continuó siendo sostenida por la organización como una consigna central hasta los últimos ejemplares de Revolución. En el número 26 figuraba, en la parte superior de la primera plana, la consigna "Hay que impedir el triunfo de la reacción. Los trabajadores deben formar su propio partido político"36. El "editorial sindical" de ese número, sin firma, sacaba la siguiente conclusión:

De los errores y traiciones actuales, de las batallas ganadas y perdidas, de la no disminuida combatividad obrera y popular han de levantarse las promociones de luchadores llamados a constituir la vanguardia revolucionaria de la clase obrera y del pueblo todo. Este es el camino que llevará a la constitución de un poderoso partido revolucionario. ${ }^{37}$

Que no era simplemente una exhortación de la dirección sino una línea abrazada por el conjunto de los praxistas lo demuestra que diversos militantes expresaban en sus contribuciones periodísticas la misma conclusión: era necesario un partido de combate para alcanzar el poder. Néstor Rojo, por ejemplo, finalizaba su balance de la huelga bancaria defendiendo "la necesidad imperiosa que la cl[a]se obrera tiene de contar con un partido revolucionario que la conduzca hasta el poder" ${ }^{38}$. O Pablo Emati, en una nota sobre el gremio de choferes de colectivos:

(...) la formación de un partido, organizado, dirigido y activado por militantes obreros tiene que ser la nueva meta para tiempos nuevos. (...)

\footnotetext{
${ }^{35}$ Marcos Kaplan, "Seguidismo oportunista o realismo revolucionario", en Revolución nro. 23 (marzo de 1959), pp. 1-2.

${ }^{36}$ Revolución nro. 26 (junio de 1959), p. 1.

37 "Las actuales direcciones sindicales son, en su gran mayoría, inadecuadas para las necesidades del movimiento obrero", en Revolución nro. 26 (junio de 1959), p. 4.

${ }^{38}$ Néstor Rojo, “Otra vez los bancarios”, en Revolución nro. 25 (mayo de 1959), p. 1.
} 
Que el mes de Mayo [sic], que inicia su primer día recordando el martirio de los ahorcados en Chicago, nos sirva para iniciar, todos los días juntos, esta tarea en que estamos empeñados, ir dando las bases del instrumento no ya sólo de defensa, sino de ofensiva y ataque: el Partido Revolucionario de los trabajadores. ${ }^{39}$

Claudio Perinetti se distinguió por insistir reiteradamente con la misma conclusión. Escribía en abril de 1959 que "debemos tomar conciencia de la necesidad de un partido revolucionario de los trabajadores" 40 . Y en julio del mismo año: "la lucha sindical es impotente en las actuales circunstancias si no se la enlaza con una lucha pol[ít]ica revolucionaria, para lo cual es imprescindible el Partido Obrero que las conduzca hacia la conquista del poder del Estado"

A partir de mayo de 1959 la dirección de la organización comenzó a reconocer públicamente que se debía a sí misma una elaboración más precisa acerca de los pasos concretos que había que dar para crear un partido político obrero y revolucionario. Es así que Perinetti terminaba su "editorial sindical" con estas palabras:

Lo necesario, y aquí reside el dramático déficit de la situación actual, es el urgente enraizamiento de una vanguardia revolucionaria que esclarezca, organice y conduzca ese caudal de experiencia proletaria hacia los objetivos realmente superadores de los problemas obreros y nacionales: la creación del Partido Obrero, primero y la conquista del poder político después. (...)

Tal es nuestra concepción de las tareas que debe afrontar el movimiento obrero. Por eso el MIR (PRAXIS) ha erigido como eje de su acción el impulsar la constitución de un programa, una vanguardia, y un Partido Obrero Revolucionario. (...) Para escapar de la trampa y pasar a la ofensiva, para comprender la necesidad e import[a]ncia del P[a]rtido $\mathrm{O}[\mathrm{br}]$ ero como instrumento del necesario ascenso político de los trabajadores, es imprescindible criticar el camino recorrido y evitar la repetición de funestos errores asimilando las enseñanzas de la realidad. (...) Recorrer el camino ascendente que lleva a tales metas implica respetar un lógico escalonamiento de etapas tácticas. Los recientes artículos del compañero Marcos Kaplan, y los esbozos planteados desde estas columnas en números anteriores de "Revolución", han delineado la concepción que el MIR (PRAXIS) sostiene ante estas tareas. No obstante, la vigente necesidad de afrontar su aplicación práctica nos mueve a prometer un compendio de nuestro programa táctico para los próximos números. ${ }^{42}$

\footnotetext{
${ }^{39}$ Pablo Emati, “La movilización en la Unión Transportes Automotor", en Revolución nro. 25 (mayo de 1959), p. 4, subrayado nuestro.

${ }^{40}$ Claudio Perinetti, "Encrucijada obrera”, en Revolución nro. 24 (abril de 1959), p. 4.

${ }^{41}$ Claudio Perinetti, "Mientras el gobierno gana tiempo muchos dirigentes sindicales lo pierden”, en Revolución nro. 27 (julio de 1959), p. 4.

${ }^{42}$ Claudio Perinetti, "1 de mayo de 1959: la clase obrera debe transformar la resistencia en ofensiva", en Revolución nro.
} 
Una primera respuesta la dio Marcos Kaplan en el número siguiente:

La única alternativa viable para la crisis argentina pasa por el reagrupamiento de los mejores elementos del proletariado, de la pequeña burguesía pobre y productiva, de la intelectualidad esclarecida y de los militantes sanos del movimiento obrero y la izquierda, en un poderoso movimiento capaz de enraizarse en las masas, de esclarecerlas y organizarlas, y de luchar contra las influencias reaccionarias de la derecha y los centristas. (...) trabajamos por promover un reagrupamiento revolucionario, una fuerza nueva, con ideología absolutamente coherente y con principios definidos, tendientes a interpretar y satisfacer las necesidades de la masa popular, en todo lo cual el proletariado dará la dirección, el impulso decisivo y la tónica dominante.

En números anteriores de REVOLUCIÓN (véase [sic] los artículos sindicales de Claudio Perinetti, la serie "Seguidismo oportunista o realismo revolucionario", etc.) hemos esbozado c[ó]mo entendemos la tarea de construir una nueva dirección revolucionaria. En los próximos números volveremos a tratar con mayor detalle este problema. ${ }^{43}$

En el siguiente número Kaplan volvió a esquivar una definición sobre el punto. Y luego de eso no firmó ningún artículo en Revolución hasta el último número, en mayo de 1960, cuando vio la luz la primera entrega de su trabajo Política y vida cotidiana, luego publicado como folleto.

\section{El viraje}

Fue en agosto de 1959 cuando S. Frondizi comenzó a hacer público un viraje.

La primera condición es ganar la confianza de la masa, con una acción amplia y profunda. Amplia, a través de la formación de un frente clasista que agrupe a todas las fuerzas populares en un poderoso movimiento de liberación, profundo, por medio de un programa avanzado y una acción integral. (...) Si conseguimos llevar al ánimo de las masas populares la conciencia de que se trabaja para su liberación integral la crisis argentina estará superada. Pero esa conciencia no será alcanzada sin un plan integral; tengo a este respecto el firme convencimiento de que las agrupaciones progresistas han menospreciado la jerarquía de los hombres del pue[b]lo, y han creído que era suficiente hablarles de la solución de los problemas económicos y hacerlo en forma abstracta y general.

La realidad es totalmente distinta; el hombre del pueblo es ante todo y sobre todo, un hombre total; es decir un hombre que produce, tiene

25 (mayo de 1959), p. 1.

${ }^{43}$ Marcos Kaplan, "Lo que nos espera, si no lo impedimos", en Revolución nro. 26 (junio de 1959), p. 3. 
afectos y pasiones, se instruye, se divierte y desea la solución de estos problemas no sólo por medio de una solución doctrinaria, sino también a través de los grandes y pequeños episodios de la vida cotidiana.

Estoy convencido que la única forma de triunfar es la de enfrentar la totalidad de los problemas, desde los más pequeños hasta los más grandes; desde aquellos que pueden referirse al mejor aprovechamiento de los alimentos, hasta los grandes problemas científicos. Demostremos que somos capaces de reemplazar a la burguesía y reemplazarla con ventaja, en todos los ámbitos del hacer humano.

Si realizamos tal cosa, conseguiremos, no sólo que la masa popular y en particular el proletariado se ponga en marcha, sino también que se incorporen millares de jóvenes de la pequeña burguesía, que sienten íntimamente la gravedad de la crisis y no están dispuestos a aceptar pasivamente su anonadamiento como personas.

Solamente un nuevo estilo de vida y de trabajo podrá salvar al hombre y al país. ${ }^{44}$

Frondizi extendía el concepto de "integralidad", que Kaplan había aplicado a los militantes, hasta abarcar el conjunto de la acción política, pero introducía una veta populista con sus referencias al "hombre de pueblo". Más importante sin embargo es que está aludiendo a las tareas de los revolucionarios sin tener en cuenta la necesidad de construir un partido, aunque no la niegue explícitamente. En cambio, aparece aquí por primera vez la idea de "un frente clasista que agrupe a todas las fuerzas populares en un poderoso movimiento de liberación", formulación ambigua que lo aleja del frente único y lo acerca al frente popular. Cabe aclarar que en los escritos que había publicado durante 1959, el hermano del presidente no había hecho ninguna referencia al partido, pero tampoco había tocado el punto relativo a las tareas prácticas del MIR-P. En julio había dado una conferencia en la que proponía un replanteo de su concepción teórica anterior, pero sin aludir a las consecuencias políticas del mismo.

Las nuevas ideas que estaba haciendo públicas Silvio Frondizi, figura más importante del MIR-P, no implicaron que desde el periódico dejara de sostenerse la necesidad de construcción de un partido revolucionario. Varios militantes mantuvieron la defensa del partido a través de Revolución. Así se expresaba Perinetti:

La historia mundial del movimiento obrero y nuestra experiencia nacional demuestran que el sindicalismo por sí solo no engendra a la vanguardia político-revolucionaria del proletariado. Por eso "Revolución" brega constantemente por la formación de un Partido Obrero y por eso también el MIR (PRAXIS) pretende constituirse en su núcleo polarizador. ${ }^{45}$

\footnotetext{
${ }^{44}$ Silvio Frondizi, "Un nuevo estilo de vida y de trabajo salvará al hombre y al país", en Revolución nro. 28 (agosto de 1959), p. 1.

${ }^{45}$ Claudio Perinetti, “Zafra de obreros en Tucumán”, en Revolución nro. 28 (agosto de 1959), p. 1.
} 
Lo mismo vale para otros organismos del MIR-P.

Por eso sostenemos que la tarea fundamental de la hora es la construcción de un PARTIDO OBRERO REVOLUCIONARIO, que enarbole un programa basado en la planificación social, bajo control obrero, de los recursos y riquezas nacionales. Un partido y un programa que agrupe en torno a la clase obrera, a todos los restantes sectores explotados de la población.

Repetimos, este es el único camino que puede dar sentido a nuestras luchas actuales. Sabemos que muchos dirigentes han renunciado de antemano a la empresa. Los trabajadores comprendemos los errores; pero no perdonaremos la pasividad o la traición.

Las filas de la clase obrera argentina tienen las reservas suficientes para cubrir las deserciones. ${ }^{46}$

El partido continuaba siendo defendido, además, como instrumento de combate para alcanzar el poder del Estado.

Otro sería el panorama si las conquistas sindicales del proletariado se ensamblen [sic] en la perspectiva de una lucha política; si junto a la presión gremial se organizaran las tareas mínimas para el afrontamiento de un ataque político: preparación de la vanguardia proletaria y construcción del Partido Obrero que, superando los métodos sindicales de defensa se lance al aniquilamiento del Estado burgués y a la instauración del Estado proletario $(. . .)^{47}$

El acto terrorista, ligado a una inorgánica y difusa prédica insurreccional dirigida contra un gobierno, nunca puede reemplazar a la acción revolucionaria dirigida y encauzada por un partido obrero que señale al proletariado el verdadero objetivo de su lucha: la superación revolucionaria del sistema capitalista y el poder del estado en manos de la clase obrera. ${ }^{48}$

Esta conclusión fue elegida para ser transcrita en la primera plana del periódico a modo de resumen de la nota. Suficientemente explícito es el artículo titulado "La juventud y el partido revolucionario (aproximaciones)", el cual finaliza bregando por el "partido revolucionario que la clase obrera y los sectores explotados buscan a tientas" 49 . Lo mismo vale para un texto firmado por Bernardo Zaldívar: "Sin teoría [y] práctica revolucionarias, no hay partido revolucionario" ${ }^{50}$. Un artículo sobre la provincia de Catamarca consideraba

\footnotetext{
${ }^{46}$ Comando Metalúrgico del Movimiento Izquierda Revolucionaria (Praxis), "Metalúrgicos: comunicado al gremio", en Revolución nro. 28 (agosto de 1959), p. 4, mayúsculas y subrayado en el original.

${ }^{47}$ Sección Matanzas del Movimiento Izquierda Revolucionaria, "Frigorífico: pro y contra de la cooperativa obrera", en Revolución nro. 28 (agosto de 1959), p. 4.

48 “Terrorismo o revolución”, en Revolución nro. 29 (septiembre de 1959), pp. 1 y 3.

49 "La juventud y el partido revolucionario", en Revolución nro. 29 (septiembre de 1959), p. 2.

${ }^{50}$ Bernardo Zaldívar, "Desencuentro de la juventud socialista", en Revolución nro. 30 (octubre-noviembre de 1959), p. 3.
} 
que "la única salida verdadera" era la "agrupación de la clase obrera en el Partido Revolucionario de los trabajadores" $"$.

En octubre de 1959 Claudio Perinetti reconocía que el reagrupamiento promovido por Praxis no prosperaba todavía: "La superación de esta encrucijada se logrará cuando prospere el reagrupamiento de una vanguardia obrera decidida a encauzar la lucha por un rumbo político y revolucionario" 52 .

A comienzos de 1960 Silvio Frondizi publicó un artículo en Revolución en el que introdujo dos elementos que hasta ese momento eran ajenos al discurso praxista.

Nosotros tampoco creemos en la solución Perón: éste no regresará y si lo hace se mantendrá muy poco en el poder, porque a la crisis general debe agregarse la toma de conciencia de la masa peronista que le exigirá medidas drásticas, cuyo incumplimiento le significaría la caída en el desprestigio a corto plazo. Y en la tercera variante, si regresara y tomara el camino revolucionario, bienvenido sea Perón: Máxime cuando en esas condiciones tendría que recurrir necesaria y fatalmente a las fuerzas de izquierda.

John William Cooke ya lo dijo hace poco en un documento extraordinario: el peronismo poco o nada en serio puede hacer por sí solo. Si quiere marchar adelante y cumplir su papel histórico tendrá que conjugarse con las fuerzas progresistas afines.

Lo expuesto nos permite partir de la siguiente afirmación: de que, si la crisis en que se debate el país conduce a la caída del gobierno actual, el proceso crítico seguirá adelante y no se detendrá, sino con un cambio total de estructura del país y su transformación en un estado socialista.

$\mathrm{Si}$ esto es exacto, nos enfrentamos a una doble tarea: una de preparación de los elementos técnicos que puedan dirigir la nueva sociedad. Otra de lucha para la conquista del poder.

Esta última abarcará desde la toma del control ideológico del país, pasando por la lucha en los frentes generales, la formación de los cuadros revolucionarios, hasta la lucha de guerrillas. Como en nuestros escritos nos hemos preocupado de las primeras formas de lucha, permítasenos dedicarle alguna atención a la última.

Hasta ahora el pueblo ha expresado su descontento a través de formas pasivas de lucha, tal es el significado del voto en blanco. A veces llegó, cuanto más, a huelgas más o menos violentas. La guerrilla por el contrario significa un nuevo método de lucha: la toma de la ofensiva por parte de las fuerzas revolucionarias.

(...) De aquí la desesperación de los burócratas peronistas y comunistas. Es que el mito del hombre providencial es reemplazado por una realidad viviente: el hombre de pueblo buscando y consiguiendo su propia liberación.

\footnotetext{
${ }^{51}$ Mariano Graco, “Catamarca: sigue la desocupación”, en Revolución nro. 30 (oct.-nov. de 1959), p. 4.

52 Claudio Perinetti, "Frente obrero: cumplen las bases, fracasan las direcciones", en Revolución nro. 30 (octubrenoviembre de 1959), p. 4.
} 
Es notable indicar como el problema de las guerrillas y el héroe anónimo "Uturuncu" ya ha hecho presa de la imaginación popular, en forma tal que superó a los cálculos de los más optimistas. ${ }^{53}$

Lo más interesante de este escrito es que muestra la simultaneidad con que aparecen dos actitudes de acercamiento: hacia el peronismo y hacia el guerrillerismo. En el primer caso era abandonada la caracterización de Perón como un instrumento de la burguesía nacional. Aunque pensaba que era poco probable, Frondizi admitía un eventual retorno del general exiliado. Y dando por hecho "la toma de conciencia de la masa peronista que le exigirá medidas drásticas", excluía la posibilidad de un regreso con fines contrarrevolucionarios para admitir sólo dos variantes: que Perón no cumpliera con esas exigencias, cayendo en el desprestigio, o que tomara el camino revolucionario. La similitud con la prédica de Cooke salta a la vista, y probablemente este viraje tuviera que ver con la relación con el ex diputado. "Si quiere marchar adelante y cumplir su papel histórico" ¿cuál era este papel del peronismo? Evidentemente para Frondizi no era otro que realizar las "tareas democrático-burguesas", es decir liberar al país del imperialismo. Y para hacerlo debería tomar el camino revolucionario: se trata de una apuesta por la "vía cubana", es decir por una deriva castrista del peronismo.

Las ambiguas expresiones elegidas no permiten deducir si las huelgas eran consideradas formas "pasivas" o intermedias. En cualquier caso, la guerrilla era considerada un método más avanzado, más ofensivo que las huelgas violentas. Lo más importante es que era colocada como una forma de lucha necesaria para alcanzar la conquista del poder en Argentina, tanto como "la formación de los cuadros revolucionarios" o "la lucha en los frentes generales". No se trataba de una posibilidad entre diversos modos de combate de las masas, sino de un momento insoslayable. En este punto Silvio adoptaba una posición propia del foquismo, abriendo una puerta que atravesaron muchos militantes de Praxis. Esta línea estaba desarrollada en otro artículo del mismo periódico.

(...) las masas trabajadoras y populares van buscando nuevos y mejores métodos e instrumentos de pensamiento, de acción y de combate. (...)

$\mathrm{Al}$ escribir esto pensamos en los brotes de combatividad sindical, en el fracaso de las tentativas de captación partidaria de las masas peronistas, en las informaciones dispersas sobre terrorismo, contrabando y robos de armas, ataques a puestos militares; y sobre todo, en el surgimiento de grupos guerrilleros que han operado con bastante eficacia y éxito en el Norte y también quizás en el Litoral.

\section{¿AVENTURA AISLADA O FUTURO PRÓXIMO?}

En lo que a las guerrillas respecta, se cuenta con información escasa y contradictoria. (...) Podría ocurrir que se trate de una acción aislada sin

\footnotetext{
${ }^{53}$ Silvio Frondizi, “1960: el pueblo lucha por su liberación”, en Revolución nro. 32 (febrero de 1960), p. 2.
} 
futuro. Pero podría ocurrir también que estos episodios señalen la aparición de nuevas formas de lucha y prefiguren un aspecto decisivo del porvenir argentino más o menos próximo.

Supongamos, en efecto, que -como es muy previsible- se siga agravando el proceso de entrega, miseria y opresión, y con ello la indignación y protesta de las masas, con el correlativo desprestigio de las viejas e ineficaces direcciones. Supongamos asimismo que los núcleos guerrilleros originales se mantengan y multipliquen, y que a través de sus experiencias y fracasos se vayan dando una dirección, una ideología y una organización realmente revolucionarias. Supongamos finalmente que esa dirección logre presentar una perspectiva política realista y atractiva, monte una red organizativa y militante de alcance nacional, y ejecute operaciones militares y actos de justicia social que conmuevan y atraigan a las masas populares.

En esas condiciones, los núcleos guerrilleros podrían ir apareciendo a los ojos de las masas como demostración de que la lucha revolucionaria contra la miseria y la opresión es posible con probabilidades de éxito, y por lo tanto como modelo a tener en cuenta para imitar o adaptar si la ocasión se presenta. Es útil recordar a este respecto las experiencias de China, Argelia, Bolivia y Cuba, y también que en el Norte y Oeste de la Argentina las brasas de la tradición montonera no se han apagado del todo bajo las cenizas del tiempo y de la vida burguesa más o menos normal. (...)

No ignoramos finalmente que el proceso histórico no espera ni perdona, ni tiene compromiso firmado con ninguna fuerza política, por mejores que sean sus postulados e intenciones, y que la izquierda revolucionaria puede perder el tren si no se apura y adapta a las circunstancias. ${ }^{54}$

También aquí corresponde constatar que la evidente influencia del foquismo aparece en forma simultánea a las referencias a la "tradición montonera" propias del nacionalismo.

Estas nuevas reflexiones no implicaron, al menos en lo que refiere al periódico del MIR-P, el abandono de la idea de construir un partido como medio para llegar al poder. En el mismo número de Revolución los militantes de la organización continuaban sosteniendo la fórmula leninista.

(...) la única garantía de que los obreros no van a ser echados como perros sarnosos de las fuentes de trabajo ni de sus viviendas, es desarrollando el MOVIMIENTO IZQUIERDA REVOLUCIONARIA (praxis) y formando rápidamente un PARTIDO REVOLUCIONARIO OBRERO que se proponga por todos los medios desalojar del poder del gobierno a la patronal $(\ldots) .^{55}$

\footnotetext{
54 “Guerrillas en el norte”, en Revolución nro. 32 (febrero de 1960), p. 3.

55 Sección "Villa Jardín" del Movimiento Izquierda Revolucionaria (praxis), "Detrás de un largo muro: Villa Jardín”, en Revolución nro. 32 (febrero de 1960), p. 2.
} 
(...) las luchas que sostiene la clase obrera en el orden nacional, exigen la construcción de un sólido PARTIDO REVOLUCIONARIO DE LA CLASE TRABAJADORA que en el plano político canalice a las masas obreras y populares hacia la eliminación del orden capitalista y el establecimiento de un gobierno obrero y popular. ${ }^{56}$

En un artículo central del siguiente número incluso se precisó la idea: "Somos hombres que estamos sufriendo una etapa de transición en la larga ruta organizativa que va desde un grupo de propaganda hacia una vanguardia de masas. Creemos necesario quemar y consolidar esas etapas sin las cuales el partido revolucionario no cuajará en la realidad $(\ldots)^{\prime, 57}$.

Pero, así como continuó la defensa de la construcción del partido, comenzó a desarrollarse también la idea novedosa de la necesidad de una confluencia con el ala izquierda del peronismo como camino de aquella construcción.

La izquierda peronista fundamenta su táctica política en la consigna de la vuelta de Perón como somat[é]n insurreccional que arrastraría a grandes masas hacia una revolución profunda. (...) la serie de elementos y factores de fuerza que el ala derecha del peronismo puede arrastrar en una lucha fraccional, obligan a los sectores de izquierda peronista a renovar sus hábitos políticos, su estrategia de trabajo y acción partidaria, sus consignas. La lucha se va transformando en desigual si se la mantiene en el plano de las direcciones. Es necesaria una acción de masas científicamente planificada. Sus modalidades podrían ser las siguientes:

a) Organización clandestina y celular de los elementos revolucionarios y de todas aquellas tendencias sanas y progresistas del peronismo. (...)

b) Acción de masas, pero cambiando la tónica idealista que a ésta se le daba en la consigna de la vuelta de Perón, por el planteamiento de los problemas más concretos, su esclarecimiento y dilucidación revolucionaria. (...) La acción de masas debe consolidarse en un aparato militante nuevo y vigoroso enraizado en el seno de las masas. Hay que dejar un poco el onanismo político en las burocracias sindicales para sumergirnos en las bases obreras.

c) Conexión con los movimientos de izquierda que fuera del peronismo están cumpliendo una tarea de adoctrinamiento revolucionario en las masas obreras para el reagrupamiento y formación de cuadros militantes.

d) Por su parte la izquierda revolucionaria debe ir comprendiendo que la lucha de clases encuentra campo de acción en todas las instituciones del sistema burgués. Y si la izquierda revolucionaria

\footnotetext{
56 Sección Lomas de Zamora del M.I.R. (PRAXIS), "Monte Grande: 700 obreros en la calle”, en Revolución nro. 32 (febrero de 1960), p. 4.

57 "Nuestro voto en blanco...y el de ellos", en Revolución nro. 33 (marzo de 1960), p. 2.
} 
pretende ser la vanguardia de una transformación social debe operar en todas partes, debe estar presente allí donde se aviva y se agita la lucha de clases. Dicha vanguardia surge fundamentalmente del reagrupamiento que la desintegración de las viejas fuerzas políticas va produciendo (entre ellas el peronismo). Esta desintegración implica una lucha interna cada vez más profunda y violenta en que la derecha burguesa trata de exterminar física y políticamente a aquellos sectores avanzados que luchan por desarrollar la conciencia de las masas hasta sus últimas consecuencias. Si la izquierda revolucionaria se mantiene ajena a esta realidad se reducirá a una secta microscópica, y si la izquierda peronista no renueva sus métodos de lucha y acción política caerá tarde o temprano bajo el fuego graneado de una derecha lúcida y coherente $(\ldots)^{58}$

El texto comienza refiriéndose a la izquierda peronista como a una corriente ajena a la propia, criticando su política, pero luego adopta un tono prescriptivo, postulando lo que esta tendencia debería hacer, llegando incluso a utilizar la primera persona ("Hay que... sumergirnos en las bases obreras"). Las tareas que la izquierda peronista debía encarar, además, implicaban un cambio en su táctica, pero no una ruptura con el peronismo ni con la ideología nacionalista. En definitiva, eran las mismas tareas que pretendía acometer el MIR-Praxis: acción de masas, organización clandestina y celular, dilucidación revolucionaria de los problemas concretos, aparato militante nuevo y vigoroso. La crítica era a los métodos y a los objetivos tácticos de la izquierda peronista, no a sus fines estratégicos. Se trata, indudablemente, de la continuación de los conceptos volcados por Silvio Frondizi en su nota del número anterior de Revolución.

Los últimos periódicos prueban que el discurso de la organización, expresado en artículos centrales y sin firma -evidentemente redactados o aprobados por la dirección-, continuó incluyendo la consideración de la formación del partido político como el único método para la revolución social: "La única solución efectiva está en las manos de los millones de trabajadores de esta tierra, en su organización a través de un partido con vocación para conquistar el gobierno" 59 . El balance de un conflicto en la empresa GoodYear aseguraba que la pelea "debería continuar profundizando los antiguos métodos de lucha hasta ahora empleados y desplegando una intensa acción política que deberá cristalizar el futuro partido de la clase obrera. Es la única salida"60.

Finalmente, la contratapa del último número de Revolución estuvo ocupada íntegramente por el editorial sindical, redactado por la "secretaría obrera" del MIR-P. El copete y la nota expresaban los siguientes conceptos:

SÓLO UNA TENDENCIA SINDICAL NUEVA ESCLARECIDA Y COMBATIVA ENRAIZADA EN UN PARTIDO REVOLUCIONARIO PUEDE SALVAR DEL NAUFRAGIO A QUE LAS ACTUALES

\footnotetext{
${ }^{58}$ Daniel Indarte, "La crisis del peronismo y sus tendencias en pugna", en Revolución nro. 33 (marzo de 1960), p. 3. 59 "El terreno de la lucha lo deben elegir las masas y no el gobierno", en Revolución nro. 34 (abril de 1960), p. 1.

60 "Good-Year: balance de una huelga fallida", en Revolución nro. 35 (mayo de 1960), p. 11.
} 


\section{DIRECCIONES SINDICALES LLEVARON AL MOVIM. OBRERO [sic].}

(...) Para nosotros el partido obrero debe ser el laboratorio de la revolución donde se van creando todos los factores, los instrumentos y los elementos que la realidad nos brinda, de los cuales saldrán las fórmulas tácticas y estratégicas que orienten las futuras batallas de clase. Pero como laboratorio que es el partido revolucionario no tiene sabios geniales que piensan ni militantes abnegados que obedecen. Él en su conjunto es un mecanismo de organización socialista que utiliza y aprovecha, le da sentido coherente y conclusiones programáticas a las experiencias e iniciativas individuales que nuestros compañeros, activistas y militantes adquieren en la experiencia cotidiana y en su pasión militante. (...) Las primeras aproximaciones que vamos lanzando para el reagrupamiento tras una tendencia sindical nueva, enraizada en una vanguardia política revolucionaria o partido obrero son las siguientes:

$1^{\circ}$ ) Coincidencias programáticas: La crisis del país tiene una única salida: la revolución social. Revolución Social quiere decir, insurrección popular acaudillada por la clase trabajadora (...) y dirigida por un partido revolucionario (...).

$2^{\circ}$ ) Coincidencias en un plan estratégico: (...) Debemos elaborar un plan estratégico, defensivo y ofensivo, que contemple todas las formas de lucha que va dando la realidad, les dé sentido planificado y un objetivo preciso y programático. Debemos elegir nosotros el campo de batalla y ubicar los puntos flacos del gobierno y la patronal. Toda esa actividad debe ser centralizada por un estado mayor ágil, lúcido y combativo: el partido revolucionario. ${ }^{61}$

Aunque en ciertas expresiones o metáforas militares puede entreverse la influencia de la dirección cubana, la "secretaría obrera" colocaba el énfasis en la importancia de la construcción del partido político revolucionario.

\section{Conclusión}

A lo largo de este artículo fuimos analizando cómo los militantes de Praxis elaboraron a lo largo de los años un concepto acerca de la tarea práctica que tenían por delante. En un primer momento la organización se pronunció por la construcción de un partido obrero en términos inmediatos. Más adelante, sin embargo, comenzó a desarrollarse la idea de que era necesario cumplir con una etapa previa, de formación de una vanguardia, sobre la base de la cual podría crearse finalmente el partido obrero. En una tercera etapa, que en términos generales comienza a partir del triunfo de la Revolución Cubana a comienzos de 1959, hemos comprobado la coexistencia de dos líneas: una más "novedosa" o heterodoxa, desplegada por Silvio Frondizi y Marcos Kaplan, y otra más "ortodoxa” o

\footnotetext{
61 “En el frente obrero", en Revolución nro. 35 (mayo de 1960), p. 12.
} 
"tradicional", sostenida por otra parte de los miembros del Praxis.

La necesidad del partido obrero fue aceptada por el conjunto del MIR-P. En primer lugar, por Silvio Frondizi en una línea de La Realidad Argentina, en dos artículos de fines de 1955 (reeditados por la organización tres años después), en la entrevista concedida a Carlos Strasser en 1958 y en su segura aprobación de las consignas expresadas en la prensa de Praxis. En segundo lugar, por Marcos Kaplan en sus artículos hasta 1960 y en su aprobación, como director, de los textos enviados y de las consignas y títulos que hemos citado. Hemos demostrado también que fue un componente de la línea del MIR-P aceptado por el conjunto de los militantes y en particular por el sector de la dirección y de los militantes de base que insistían con ello en los últimos números de Revolución.

Pero a lo largo del segundo lustro de la década del 50, desde que comenzó hasta que terminó la edición del periódico, se fueron definiendo dos tendencias. La línea "leninista" fue defendida con énfasis y asiduidad por un sector de la organización vinculado a la actividad sindical o proletaria. Lo evidencian los escritos de Claudio Perinetti (trabajador jabonero y encargado de los “editoriales sindicales"), Néstor Rojo (que escribía sobre el gremio bancario), Ángel Marini (empleado telefónico cuyas notas referían al sindicato), el Comando Metalúrgico y finalmente la "secretaría obrera", así como aquellos sobre conflictos en Good Year, en el frigorífico Monte Grande o sobre el sindicato de choferes de colectivos. Silvio Frondizi, en el otro extremo, evitó la construcción de una organización hasta 1955, prácticamente no tocó el punto en sus textos posteriores y desde mediados de 1959 inició un viraje político que lo fue alejando cada vez más de los postulados de Lenin sobre el partido y el frente único.

El análisis histórico de las posiciones políticas del MIR-P a través del conjunto de sus publicaciones permite iluminar mejor un punto que no había sido desarrollado en los trabajos de Tarcus y Amaral. El primero se basó, para explicar la idea de los praxistas acerca del tipo de organización que querían construir, en el folleto Política y vida cotidiana, publicado por Kaplan en 1960, al cual calificó como "un verdadero manifiesto de la nueva izquierda"62. Pero atender exclusivamente a los conceptos "neo-izquierdistas" que comenzó a desarrollar la dirección de Praxis tras la Revolución Cubana no permite dar cuenta cabalmente de la concepción política del MIR-Praxis en su totalidad y a través de su desenvolvimiento histórico. En efecto, el fragmento en el cual Frondizi sostuvo que un grupo revolucionario debía "preformar en pequeño la sociedad socialista por cuyo alumbramiento milita" "63, expresó en aquel momento simplemente un componente menor dentro del más amplio discurso praxista. El concepto de un partido como "anticipación" de la sociedad futura estuvo ausente tanto en los dos tomos de La Realidad Argentina como en el órgano de prensa del MIR-P que los militantes leían y distribuían y en el cual escribían. La idea dominante durante toda la segunda mitad de la década del 50 fue la de un partido de combate para que la clase obrera alcance el poder del Estado, es decir el concepto leninista.

En futuros trabajos intentaremos determinar en qué medida estas diferentes líneas o tendencias dentro del MIR-P permanecieron o se discontinuaron en los debates posteriores

\footnotetext{
62 Tarcus, op. cit., p. 145.

${ }^{63}$ Silvio Frondizi, "Prólogo", en Kaplan, Economía y política ..., op. cit., p. 9.
} 
de los praxistas.

\section{Bibliografía}

Fuentes impresas

Altamirano, Carlos, Bajo el signo de las masas (1943-1973), Buenos Aires, Emecé, 2007.

Brienza, Hernán, Silvio Frondizi. Un francotirador marxista, Buenos Aires, Capital Intelectual, 2006.

Coggiola, Osvaldo, Historia del trotskismo en Argentina y América Latina [1985-1986], Buenos Aires, ryr, 2006.

Frondizi, Silvio, La Realidad Argentina. Ensayo de interpretación sociológica. Tomo I: El sistema capitalista, Buenos Aires, Praxis, 1957 (2 ed.). $1^{\text {a }}$ ed.: 1955.

Doce años de política argentina, Buenos Aires, Praxis, 1958 [1945-1957].

La Realidad Argentina. Ensayo de interpretación sociológica. Tomo II: La revolución socialista, Buenos Aires, Praxis, 1960 (2 ed.). $1^{\text {a }}$ ed.: 1956.

--- "Bases y punto de partida para una solución popular", Buenos Aires, Ciencias Políticas, 1960.

La integración mundial, última etapa del capitalismo (y otros escritos), Buenos Aires, Peña Lillo / Continente, 2014 [1946-1964; selección e introducción de Juan J. Barbero].

Kaplan, Marcos, Economía y política del petróleo argentino (1939-1956), Buenos Aires, Praxis, 15 de enero de 1957.

La crisis del radicalismo, Buenos Aires, Praxis, 31 de enero de 1958.

Mattini, Luis, Los perros. Memorias de un combatiente revolucionario, Buenos Aires, Peña Lillo / Continente, 2014 (3ra ed). $1^{\text {a }}$ ed.: 2006.

Napurí, Ricardo, Pensar América Latina. Crónicas autobiográficas de un militante revolucionario, Buenos Aires, Herramienta, 2009.

Rath, Christian, "El MIR (Praxis) en la historia del movimiento obrero argentino", en En defensa del marxismo nro. 45, Buenos Aires, Rumbos, octubre de 2015, pp. 67-84.

Strasser, Carlos (coord.), Las izquierdas en el proceso político argentino, Buenos Aires, Palestra, 1959.

Tarcus, Horacio, “Silvio Frondizi, un pensamiento trágico de la crisis", en Crisis, $\mathrm{n}^{\circ}$ 56, diciembre de 1987.

"Silvio Frondizi, pensador trágico de la crisis", en Sur, suplemento "Las palabras y las cosas", 17 de junio de 1990. 
"La visión trágica en el pensamiento marxista argentino: Silvio Frondizi y

Milcíades Peña", en El cielo por asalto, n 5, otoño de 1993.

------------ El marxismo olvidado en la Argentina: Silvio Frondizi y Milcíades Peña, Buenos Aires, El cielo por asalto, 1996.

“Actualidad de Silvio Frondizi”, prólogo a Brienza, op. cit.

\section{Fuentes digitales}

Amaral, Samuel, "Silvio Frondizi y el surgimiento de la nueva izquierda", Universidad del CEMA, documento de trabajo $\mathrm{n}^{\mathrm{o}} 313,2006$, disponible online en:

http://www.ucema.edu.ar/publicaciones/download/documentos/313.pdf [consultado por última vez: 24/01/2017]

Ruiz Moreno, Sylvia, "Silvio Frondizi ante la condición humana", disponible online en http://www.ensayistas.org/critica/generales/C-H/argentina/silvio.htm, octubre de 2004 [consultado por última vez: 24/01/2017]. 